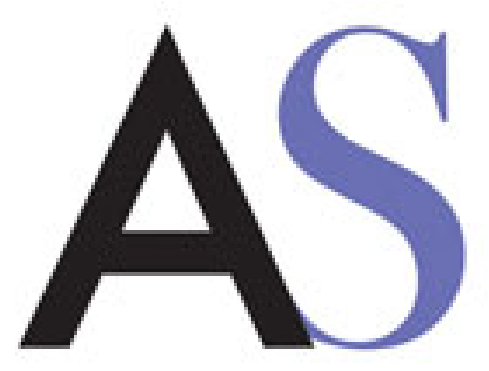

\title{
(W) WLACKWELL
}

Metaphor

Author(s): Max Black

Source: Proceedings of the Aristotelian Society, New Series, Vol. 55 (1954 - 1955), pp. 273-294

Published by: Blackwell Publishing on behalf of The Aristotelian Society

Stable URL: http://www.jstor.org/stable/4544549

Accessed: $21 / \overline{/ 09 / 2010 ~ 14: 25}$

Your use of the JSTOR archive indicates your acceptance of JSTOR's Terms and Conditions of Use, available at http://links.jstor.org/page/info/about/policies/terms.jsp. JSTOR's Terms and Conditions of Use provides, in part, that unless you have obtained prior permission, you may not download an entire issue of a journal or multiple copies of articles, and you may use content in the JSTOR archive only for your personal, non-commercial use.

Please contact the publisher regarding any further use of this work. Publisher contact information may be obtained at http://links.jstor.org/action/showPublisher?publisherCode=aristotelian.

Each copy of any part of a JSTOR transmission must contain the same copyright notice that appears on the screen or printed page of such transmission.

JSTOR is a not-for-profit service that helps scholars, researchers, and students discover, use, and build upon a wide range of content in a trusted digital archive. We use information technology and tools to increase productivity and facilitate new forms of scholarship. For more information about JSTOR, please contact support@jstor.org. 
Meeting of the Aristotelian Society at 21, Bedford Square, W.C.1, on May 23rd, 1955, at 7.30 p.m.

\section{XII-METAPHOR}

\section{By Max Black.}

"Metaphors are no arguments, my pretty maiden." (The Fortunes of Nigel, Book 2, Ch. 2.)

To draw attention to a philosopher's metaphors is to belittle him-like praising a logician for his beautiful handwriting. Addiction to metaphor is held to be illicit, on the principle that whereof one can speak only metaphorically, thereof one ought not to speak at all. Yet the nature of the offence is unclear. I should like to do something to dispel the mystery that invests the topic; but since philosophers (for all their notorious interest in language) have so neglected the subject, I must get what help I can from the literary critics. They, at least, do not accept the commandment, " Thou shalt not commit metaphor", or assume that metaphor is incompatible with serious thought.

\section{1.}

The questions I should like to see answered concern the "logical grammar" of "metaphor" and words having related meanings. It would be satisfactory to have convincing answers to the questions: "How do we recognize a case of metaphor?", "Are there any criteria for the detection of metaphors?", "Can metaphors be translated into literal expressions?", "Is metaphor properly regarded as a decoration upon "plain sense' ?", "What are the relations between metaphor and simile?", "In what sense, if any, is a metaphor "creative '?", "What is the point of using a metaphor?". (Or, more briefly, "What do we mean by 'metaphor'? ". The questions express attempts to become clearer about some uses of the word "metaphor" -or, if one prefers the material mode, to analyze the notion of metaphor.) 
The list is not a tidy one, and several of the questions overlap in fairly obvious ways. But I hope they will sufficiently illustrate the type of inquiry that is intended.

It would be helpful to be able to start from some agreed list of " clear cases" of metaphor. Since the word "metaphor" has some intelligible uses, however vague or vacillating, it must be possible to construct such a list. Presumably, it should be easier to agree whether any given item should be included than to agree about any proposed analysis of the notion of metaphor.

Perhaps the following list of examples, chosen not altogether at random, might serve:cussion."

(i) "The chairman ploughed through the dis-

(ii) " A smoke-screen of witnesses."

(iii) "An argumentative melody."

(iv) " Blotting-paper voices" (Henry James).

(v) "The poor are the negroes of Europe" (Baudelaire).

(vi) "Light is but the shadow of God" (Sir Thomas Browne).

(vii) "Oh dear white children, casual as birds. Playing amid the ruined languages"

(Auden).

I hope all these will be accepted as unmistakeable instances of metaphor, whatever judgements may ultimately be made about the meaning of "metaphor". The examples are offered as clear cases of metaphor, but, with the possible exception of the first, they would be unsuitable as "paradigms". If we wanted to teach the meaning of " "metaphor" to a child, we should need simpler examples, like " The clouds are crying " or " The branches are fighting with one another". (Is it significant that one hits upon examples of personification?) But I have tried to include some reminders of the possible complexities that even relatively straightforward metaphors may generate.

Consider the first example-" The chairman ploughed through the discussion". An obvious point to begin with is the contrast between the word "ploughed " and the remain- 
ing words by which it is accompanied. This would be commonly expressed by saying that "ploughed" has here a metaphorical sense, while the other words have literal senses. Though we point to the whole sentence as an instance (a " clear case") of metaphor, our attention quickly narrows to a single word, whose presence is the proximate reason for the attribution. And similar remarks can be made about the next four examples in the list, the crucial words being, respectively, " smoke-screen ", " argumentative ", " blotting paper", and " negroes".

(But the situation is more complicated in the last two examples of the list. In the quotation from Sir Thomas Browne, "Light" must be supposed to have a symbolic sense, and certainly to mean far more than it would in the context of a text-book on optics. Here, the metaphorical sense of the expression, "the shadow of God" imposes a meaning richer than usual upon the subject of the sentence. Similar effects can be noticed in the passage from Auden (consider for instance the meaning of "white" in the first line). I shall have to neglect such complexities in this paper.)

In general, when we speak of a relatively simple metaphor, we are referring to a sentence or another expression, in which some words are used metaphorically, while the remainder are used non-metaphorically. An attempt to construct an entire sentence of words that are used metaphorically results in a proverb, an allegory, or a riddle. No preliminary analysis of metaphor will satisfactorily cover even such trite examples as "In the night all cows are black". And cases of symbolism (in the sense in which Kafka's castle is a "symbol ") also need separate treatment.

\section{2.}

"The chairman ploughed through the discussion." In calling this sentence a case of metaphor, we are implying that at least one word (here, the word "ploughed") is being used metaphorically in the sentence, and that at least one of the remaining words is being used literally. 
Let us call the word "ploughed" the focus of the metaphor, and the remainder of the sentence in which that word occurs the frame. (Are we now using metaphors-and mixed ones at that? Does it matter?) One notion that needs to be clarified is that of the "metaphorical use" of the focus of a metaphor. Among other things, it would be good to understand how the presence of one frame can result in metaphorical use of the complementary word, while the presence of a different frame for the same word fails to result in metaphor.

If the sentence about the chairman's behaviour is translated word for word into any foreign language for which this is possible, we shall of course want to say that the translated sentence is a case of the very same metaphor. So, to call a sentence an instance of metaphor is to say something about its meaning, not about its orthography, its phonetic pattern, or its grammatical form. ${ }^{1}$ (To use a well-known distinction, "metaphor" must be classified as a term belonging to " semantics" and not to " syntax" - or to any physical inquiry about language.)

Suppose somebody says, "I like to plough my memories regularly". Shall we say he is using the same metaphor as in the case already discussed, or not? Our answer will depend upon the degree of similarity we are prepared to affirm on comparing the two "frames" (for we have the same "focus" each time). Differences in the two frames will produce some differences in the interplay ${ }^{2}$ between focus and frame in the two cases. Whether we regard the differences as sufficiently striking to warrant calling the sentences two metaphors is a matter for arbitrary decision. "Metaphor" is a loose word, at best, and we must beware of attributing to it stricter rules of usage than are actually found in practice.

So far, I have been treating " metaphor" as a predicate properly applicable to certain expressions, without attention

${ }^{1}$ Any part of speech can be used metaphorically (though the results are meagre and uninteresting in the case of conjunctions); any form of verbal expression may contain a metaphorical focus.

${ }^{2}$ Here I am using language appropriate to the "interaction view" of metaphor that is discussed later in this paper. 
to any occasions on which the expressions are used, or to the thoughts, acts, feelings, and intentions of speakers upon such occasions. And this is surely correct for some expressions. We recognize that to call a man a "cesspool" is to use a metaphor, without needing to know who uses the expression, or on what occasions, or with what intention. The rules of our language determine that some expressions must count as metaphors; and a speaker can no more change this than he can legislate that "cow" shall mean the same as "sheep". But we must also recognize that the established rules of language leave wide latitude for individual variation, initiative, and creation. There are indefinitely many contexts (including nearly all the interesting ones) where the meaning of a metaphorical expression has to be reconstructed from the speaker's intentions (and other clues) because the broad rules of standard usage are too general to supply the information needed. When Churchill, in a famous phrase, called Mussolini "that utensil", the tone of voice, the verbal setting, the historical background, helped to make clear what metaphor was being used. (Yet, even here, it is hard to see how the phrase " that utensil " could ever be applied to a man except as an insult. Here, as elsewhere, the general rules of usage function as limitations upon the speaker's freedom to mean whatever he pleases.) This is an example, though still a simple one, of how recognition and interpretation of a metaphor may require attention to the particular circumstances of its utterance.

It is especially noteworthy that there are, in general, no standard rules for the degree of weight or emphasis to be attached to a particular use of an expression. To know what the user of a metaphor means, we need to know how "seriously" he treats the metaphorical focus. (Would he be just as content to have some rough synonym, or would only that word serve? Are we to take the word lightly, attending only to its most obvious implications-or should we dwell upon its less immediate associations?) In speech we can use emphasis and phrasing as clues. But in written or printed discourse, even these rudimentary aids are absent. 
Yet this somewhat elusive "weight" of a (suspected or detected $^{3}$ ) metaphor is of great practical importance in exegesis.

To take a philosophical example. Whether the expression "logical form" should be treated in a particular frame as having a metaphorical sense will depend upon the extent to which its user is taken to be conscious of some supposed analogy between arguments and other things (vases, clouds, battles, jokes) that are also said to have "form". Still more will it depend upon whether the writer wishes the analogy to be active in the minds of his readers; and how much his own thought depends upon and is nourished by the supposed analogy. We must not expect the "rules of language" to be of much help in such inquiries. (There is accordingly a sense of "metaphor" that belongs to "pragmatics", rather than to "semantics" -and this sense may be the one most deserving of attention.)

3.

Let us try the simplest possible account that can be given of the meaning of " The chairman ploughed through the discussion ", to see how far it will take us. A plausible commentary (for those presumably too literal-minded to understand the original) might run somewhat as follows:-

"A speaker who uses the sentence in question is taken to want to say something about a chairman and his behaviour in some meeting. Instead of saying, plainly or directly, that the chairman dealt summarily with objections, or ruthlessly suppressed irrelevance, or something of the sort, the speaker chose to use a word ('ploughed') which, strictly speaking, means something else. But an intelligent hearer can easily guess what the speaker had in mind." 4

This account treats the metaphorical expression (let us call it " $M$ ") as a substitute for some other literal

\footnotetext{
${ }^{3}$ Here, I wish these words to be read with as little " weight" as possible !

" Notice how this type of paraphrase naturally conveys some implication of fault on the part of the metaphor's author. There is a strong suggestion that he ought to have made up his mind as to what he really wanted to say-the metaphor is depicted as a way of glossing over unclarity and vagueness.
} 
expression (" $L$ ", say) which would have expressed the same meaning, had it been used instead. On this view, the meaning of $M$, in its metaphorical occurrence, is just the literal meaning of $L$. The metaphorical use of an expression consists, on this view, of the use of that expression in other than its proper or normal sense, in some context that allows the improper or abnormal sense to be detected and appropriately transformed. (The reasons adduced for so remarkable a performance will be discussed later.)

Any view which holds that a metaphorical expression is used in place of some equivalent literal expression, I shall call a substitution view of metaphor. (I should like this label to cover also any analysis which views the entire sentence that is the locus of the metaphor as replacing some set of literal sentences.) Until recently, one or another form of a substitution view has been accepted by most writers (usually literary critics or writers of books on rhetoric) who have had anything to say about metaphor.

To take a few examples. Whately defines a metaphor as "a word substituted for another on account of the Resemblance or Analogy between their significations."5 Nor is the entry in the Oxford Dictionary (to jump to modern times) much different from this: "Metaphor: The figure of speech in which a name or descriptive term is transferred to some object different from, but analogous to, that to which it is properly applicable; an instance of this, a metaphorical expression." 6 So strongly entrenched is the view expressed by these definitions that a recent writer who

${ }^{5}$ Richard Whately, Elements of Rhetoric (7th revised ed., London, 1846), p. 280.

"Under "Figure" we find: "Any of the various 'forms" of expression, deviating from the normal arrangement or use of words, which are adopted in order to give beauty, variety, or force to a composition; e.g., Aposiopesis, Hyperbole, Metaphor, etc." If we took this strictly we might be led to say that a transfer of a word not adopted for the sake of introducing " beauty, variety, or force" must necessarily fail to be a case of metaphor. Or will "variety" automatically cover every transfer? It will be noticed that the O.E.D.'s definition is no improvement upon Whately's. Where he speaks of a " word" being substituted, the O.E.D. prefers " name or descriptive term." If this is meant to restrict metaphors to nouns (and adjectives?) it is demonstrably mistaken. But, if not, what is " descriptive term " supposed to mean? And why has Whately's reference to "Resemblance or Analogy" been trimmed into a reference to analogy alone? 
is explicitly arguing for a different and more sophisticated view of metaphor, nevertheless slips into the old fashion by defining metaphor as "saying one thing and meaning another."?

According to a substitution view, the focus of a metaphor, the word or expression having a distinctively metaphorical use within a literal frame, is used to communicate a meaning that might have been expressed literally. The author substitutes $M$ for $L$; it is the reader's task to invert the substitution, by using the literal meaning of $M$ as a clue to the intended literal meaning of $L$. Understanding a metaphor is like deciphering a code or unravelling a riddle.

If we now ask why, on this view, the writer should set his reader the task of solving a puzzle, we shall be offered two types of answer. The, first is that there may, in fact, be no literal equivalent, $L$, available in the language in question. Mathematicians spoke of the " leg" of an angle because there was no brief literal expression for a bounding line; we say "cherry lips", because there is no form of words half as convenient for saying quickly what the lips are like. Metaphor plugs the gaps in the literal vocabulary (or, at least, supplies the want of convenient abbreviations). So viewed, metaphor is a species of catachresis, which I shall define as the use of a word in some new sense in order to remedy a gap in the vocabulary. Catachresis is the putting of new senses into old words. ${ }^{8}$ But if a catachresis serves a genuine need, the new sense introduced will quickly become part of the literal sense. "Orange" may originally have been applied to the colour by catachresis; but the word is now applied to the colour just as "properly" (and un-

"Owen Barfield, " Poetic Diction and Legal Fiction," in Essays Presented to Charles Williams (Oxford, 1947), pp. 106-127. The definition of metaphor occurs on p. 111, where metaphor is treated as a special case of what Barfield calls " tarning". The whole essay deserves to be read.

${ }^{8}$ The O.E.D. defines catachresis as: "Improper use of words; application of a term to a thing which it does not properly denote; abuse or perversion of a trope or metaphor." I wish to exclude the pejorative suggestions. There is nothing perverse or abusive in stretching old words to fit new situations. Catachresis is merely a striking case of the transformation of meaning that is constantly occurring in any living language: 
metaphorically) as to the fruit. "Osculating" curves don't kiss for long, and quickly revert to a more prosaic mathematical contact. And similarly for other cases. It is the fate of catachresis to disappear when it is successful.

There are, however, many metaphors where the virtues ascribed to catachresis cannot apply, because there is, or there is supposed to be, some readily available and equally compendious literal equivalent. Thus in the somewhat unfortunate example, ${ }^{9}$ "Richard is a lion ", which modern writers have discussed with boring insistence, the literal meaning is taken to be the same as that of the sentence, "Richard is brave".10 Here, the metaphor is not supposed to enrich the vocabulary.

When catachresis cannot be invoked, the reasons for substituting an indirect, metaphorical, expression are taken to be stylistic. We are told that the metaphorical expression may (in its literal use) refer to a more concrete object than would its literal equivalent; and this is supposed to give pleasure to the reader (the pleasure of having one's thoughts diverted from Richard to the irrelevant lion). Again, the reader is taken to enjoy problem-solving-or to delight in the author's skill at half-concealing, half-revealing his meaning. Or metaphors provide a shock of " agreeable surprise"-and so on. The principle behind these " explanations" seems to be: When in doubt about some peculiarity of language, attribute its existence to the pleasure it gives a reader. A principle that has the merit of working well in default of any evidence. ${ }^{11}$

${ }^{9}$ Can we imagine anybody saying this nowadays and seriously meaning anything? I find it hard to do so. But in default of an authentic context of use, any analysis is liable to be thin, obvious and unprofitable.

${ }^{10}$ A full discussion of this example, complete with diagrams, will be found in Gustaf Stern's Meaning and Change of Meaning (Göteborgs Högskolas Arsskrift, vol. 38, 1932, part 1), pp. $300 \mathrm{ff}$. Stern's account tries to show how the reader is led by the context to select from the connotation of " lion" the attribute (bravery) that will fit Richard the man. I take him to be defending a form of the substitution view.

${ }^{11}$ Aristotle ascribes the use of metaphor to delight in learning; Cicero traces delight in metaphor to the enjoyment of the author's ingenuity in overpassing the immediate, or in the vivid presentation of the principal subject. For references to these and other traditional views, see E. M. Cope, An Introduction to Aristotle's Rhetoric (London, 1867), "Appendix B to Book III, Ch. II: On Metaphor". 
Whatever the merits of such speculations about the reader's response, they agree in making metaphor a decoration. Except in cases where a metaphor is a catachresis that remedies some temporary imperfection of literal language, the purpose of metaphor is to entertain and divert. Its use, on this view, always constitutes a deviation from the " plain and strictly appropriate style" (Whately). ${ }^{12}$ So, if philosophers have something more important to do than give pleasure to their readers, metaphor can have no serious place in philosophical discussion.

\section{4.}

The view that a metaphorical expression has a meaning that is some transform of its normal literal meaning is a special case of a more general view about "figurative" language. This holds that any figure of speech involving semantic change (and not merely syntactic change, like inversion of normal word order) consists in some transformation of a literal meaning. The author provides, not his intended meaning, $m$, but some function thereof, $f(m)$; the reader's task is to apply the inverse function, $f^{-1}$, and so. to obtain $f^{-1}(f(m))$, i.e., $m$, the original meaning. When different functions are used, different tropes result. Thus, in irony, the author says the opposite of what he means; in hyperbole, he exaggerates his meaning; and so on.

What, then, is the characteristic transforming function involved in metaphor? To this the answer has been made: either analogy or similarity. $M$ is either similar or analogous in meaning to its literal equivalent $L$. Once the reader has detected the ground of the intended analogy or simile (with the help of the frame, or clues drawn from the wider context) he can retrace the author's path and so reach the original literal meaning (the meaning of $L$ ).

\footnotetext{
${ }^{12}$ Thus Stern (op.cit.) says of all figures of speech that "they are intended to serve the expressive and purposive functions of speech better than the "plain statement" (p. 296). A metaphor produces an "enhancement" (Steigerung) of the subject, but the factors leading to its use "involve the expressive and effective (purposive) functions of speech, not the symbolic and communicative functions" (p. 290). That is to say, metaphors may evince feelings or predispose others to act and feel in various ways-but they don't typically say anything.
} 
If a writer holds that a metaphor consists in the presentation of the underlying analogy or similarity, he will be taking what I shall call a comparison view of metaphor. When Schopenhauer called a geometrical proof a mousetrap, he was, according to such a view, saying (though not explicitly): "A geometrical proof is like a mousetrap, since both offer a delusive reward, entice their victims by degrees, lead to disagreeable surprise, etc." This is a view of metaphor as a condensed or elliptical simile. It will be noticed that a " comparison view" is a special case of a "substitution view." For it holds that the metaphorical statement might be replaced by an equivalent literal comparison.

Whately says: "The Simile or Comparison may be considered as differing in form only from a Metaphor; the resemblance being in that case stated, which in the Metaphor is implied ".13 Bain says that "The metaphor is a comparison implied in the mere use of a term " and adds, "It is in the circumstance of being confined to a word, or at most to a phrase; that we are to look for the peculiarities of the metaphor-its advantages on the one hand, and its dangers and abuses on the other ". ${ }^{14}$ This view of the metaphor, as condensed simile or comparison, has been very popular.

The chief difference between a substitution view (of the sort previously considered) and the special form of it that I have called a comparison view may be illustrated by the stock example of "Richard is a lion". On the first view, the sentence means approximately the same as "Richard is brave"; on the second, approximately the same as "Richard is like a lion (in being brave)", the added words in brackets being understood but not explicitly stated. In the second translation, as in the first, the metaphorical

13 Whately, loc. cit. He proceeds to draw a distinction between " Resemblance, strictly so called, i.e. direct resemblance between the objects themselves in question, (as when we speak of 'table-land', or compare great waves to mountains)" and "Analogy, which is the resemblance of Ratios-a similarity of the relations they bear to certain other objects; as when we speak of the ' light of reason', or of ' revelation'; or compare a wounded and captive warrior to a stranded ship ".

14 Alexander Bain, English Composition and Rhetoric (Enlarged edition, London, 1887), p. 159. 
statement is taken to be standing in place of some literal equivalent. But the comparison view provides a more elaborate paraphrase, inasmuch as the original statement is interpreted as being about lions as well as about Richard. ${ }^{15}$

The main objection against a comparison view is that it suffers from a vagueness that borders upon vacuity. We are supposed to be puzzled as to how some expression $(M)$, used metaphorically, can function in place of some literal expression $(L)$ that is held to be an approximate synonym; and the answer offered is that what $M$ stands for (in its literal use) is similar to what $L$ stands for. But how informative is this? There is some temptation to think of similarities as "objectively given", so that a question of the form, "Is $A$ like $B$ in respect of $P$ ?" has a definite and predetermined answer. If this were so, similes might be governed by rules as strict as those controlling the statements of physics. But likeness always admits of degrees, so that a truly "objective" question would need to take some such form as "Is $A$ more like $B$ than like $C$ in respect of $P$ ? "- -or, perhaps, "Is $A$ closer to $B$ than to $C$ on such and such a scale of degrees of $P$ ? " Yet, in proportion as we approach such forms, metaphorical statements lose their effectiveness and their point. We need the metaphors in just the cases when there can be no question as yet of the precision of scientific statement. Metaphorical statement is not a substitute for a formal comparison or any other kind of literal statement, but has its own distinctive capacities and achievements. Often we say, " $X$ is $M$ ", evoking some imputed connexion between $M$ and an imputed $L$ (or, rather, to an indefinite system, $L_{1}, L_{2}, L_{3}$, . . . .) in cases where, prior to the construction of the metaphor, we would have been hard put to it to find any literal resemblance between $M$ and $L$. It would be more illuminating in some

\footnotetext{
${ }^{15}$ Comparison views probably derive from Aristotle's brief statement in the Poetics: "Metaphor consists in giving the thing a name that belongs to something else; the transference being either from genus to species, or from species to genus, or from species to species, or on grounds of analogy" $(1457 b)$. I have no space to give Aristotle's discussion the detailed examination it deserves. An able defence of a view based on Aristotle will be found in S. J. Brown's The World of Imagery (London, 1927, especially pp. $67 \mathrm{ff}$ ).
} 
of these cases to say that the metaphor creates the similarity than to say that it formulates some similarity antecedently existing. ${ }^{16}$

5.

I turn now to consider a type of analysis which I shall call an interaction view of metaphor. This seems to me to be free from the main defects of substitution and comparison views and to offer some important insight into the uses and limitations of metaphor. ${ }^{17}$

Let us begin with the following statement: "In the simplest formulation, when we use a metaphor we have two thoughts of different things active together and supported by a single word, or phrase, whose meaning is a resultant of their interaction." 18

We may discover what is here intended by applying Richard's remark to our earlier example, "The poor are the negroes of Europe". The substitution view, at its crudest, tells us that something is being indirectly said about the poor of Europe. (But what? That they are an oppressed class, a standing reproach to the community's official ideals, that poverty is inherited and indelible?) The comparison view claims that the epigram presents some comparison between the poor and the negroes. In opposition

\footnotetext{
${ }^{16}$ Much more would need to be said in a thorough examination of the comparison view. It would be revealing, for instance, to consider the contrasting types of case in which a formal comparison is preferred to a metaphor. A comparison is often a prelude to an explicit statement of the grounds of resemblance; whereas we do not expect a metaphor to explain itself. (Cf. the difference between comparing a man's face with a wolf mask, by looking for points of resemblance-and seeing the human face as vulpine.) But no doubt the line between some metaphors and some similes is not a sharp one.

${ }_{17}$ The best sources are the writings of I. A. Richards, especially Chapter 5 ("Metaphor") and Chapter 6 ("Command of Metaphor") of his The Philosophy of Rhetoric (Oxford, 1936). Chapters 7 and 8 of his Interpretation in Teaching (London, 1938) cover much the same ground. W. Bedell Stanford's Greek Metaphor (Oxford, 1936) defends what he calls an " integration theory" (see especially pp. $101 \mathrm{ff}$ ) with much learning and skill. Unfortunately, both writers have great trouble in making clear the nature of the positions they are defending. Chapter 18 of W. Empson's The Structure of Complex Words (London, $195 \mathrm{I}$ ) is a useful discussion of Richard's views on metaphor.

${ }_{18}$ The Philosophy of Rhetoric, p. 93. Richards also says that metaphor is " fundamentally a borrowing between and intercourse of thoughts, a transaction between contexts" (p. 94). Metaphor, he says, requires two ideas "which co-operate in an inclusive meaning "(p. 119).
} 
to both, Richards says that our " thoughts" about European poor and (American) negroes are "active together" and " interact" to produce a meaning that is a resultant of that interaction.

I think this must mean that in the given context the focal word "negroes" obtains a new meaning, which is not quite its meaning in literal uses, nor quite the meaning which any literal substitute would have. The new context (the "frame" of the metaphor, in my terminology) imposes extension of meaning upon the focal word. And I take Richards to be saying that for the metaphor to work the reader must remain aware of the extension of meaning must attend to both the old and the new meanings together. ${ }^{19}$

But how is this extension or change of meaning brought about? At one point, Richards speaks of the "common characteristics" of the two terms (the poor and negroes) as "the ground of the metaphor" (op. cit., p. 117), so that in its metaphorical use a word or expression must connote only a selection from the characteristics connoted in its literal uses. This, however, seems a rare lapse into the older and less sophisticated analyses he is trying to supersede. ${ }^{20}$ $\mathrm{He}$ is on firmer ground when he says that the reader is forced to "connect" the two ideas (p. 125). In this " connexion" resides the secret and the mystery of metaphor. To speak of the "interaction" of two thoughts " active together" (or, again, of their "interillumination" or "co-operation") is to use a metaphor emphasizing the dynamic aspects of a good reader's response to a nontrivial metaphor. I have no quarrel with the use of metaphors (if they are good ones) in talking about metaphor. But it may be as well to use several, lest we are misled by the adventitious charms of our favourities.

Let us try, for instance, to think of a metaphor as a filter. Consider the statement, "Man is a wolf". Here, we may say, are two subjects-the principal subject, Man

10 It is this, perhaps, that leads Richards to say that " talk about the identification or fusion that a metaphor effects is nearly always misleading and pernicious" (op. cit., p. 127).

${ }^{20}$ Usually, Richards tries to show that similarity between the two terms is at best part of the basis for the interaction of meanings in a metaphor. 
(or: men) and the subsidiary subject, Wolf (or: wolves). Now the metaphorical sentence in question will not convey its intended meaning to a reader sufficiently ignorant about wolves. What is needed is not so much that the reader shall know the standard dictionary meaning of "wolf" - or be able to use that word in literal senses-as that he shall know what I will call the system of associated commonplaces. Imagine some layman required to say, without taking special thought, those things he held to be true about wolves; the set of statements resulting would approximate to what I am here calling the system of commonplaces associated with the word "wolf". I am assuming that in any given culture the responses made by different persons to the test suggested would agree rather closely, and that even the occasional expert, who might have unusual knowledge of the subject, would still know " what the man in the street thinks about the matter". From the expert's stand-. point, the system of commonplaces may include half-truths or downright mistakes (as when a whale is classified as a fish); but the important thing for the metaphor's effectiveness is not that the commonplaces shall be true, but that they should be readily and freely evoked. (Because this is so, a metaphor that works in one society may seem preposterous in another. Men who take wolves to be reincarnations of dead humans will give the statement "Man is a wolf" an interpretation different from the one $I$ have been assuming.)

To put the matter in another way: Literal uses of the word "wolf" are governed by syntactical and semantical rules, violation of which produces nonsense or self-contradiction. In addition, I am suggesting, literal uses of the word normally commit the speaker to acceptance of a set of standard beliefs about wolves (current platitudes) that are the common possession of the members of some speech community. To deny any such piece of accepted commonplace (e.g., by saying that wolves are vegetarians-or easily domesticated) is to produce an effect of paradox and provoke a demand for justification. A speaker who says " wolf" is normally taken to be implying in some sense of that word 
that he is referring to something fierce, carnivorous, treacherous, and so on. The idea of a wolf is part of a system of ideas, not sharply delineated, and yet sufficiently definite to admit of detailed enumeration.

The effect, then, of (metaphorically) calling a man a " wolf" is to evoke the wolf-system of related commonplaces. If the man is a wolf, he preys upon other animals, is fierce, hungry, engaged in constant struggle, a scavenger, and so on. Each of these implied assertions has now be made to fit the principal subject (the man) either in normal or in abnormal senses. If the metaphor is at all appropria e, this can be done-up to a point at least. A suitable hearer will be led by the wolf-system of implications to construct a corresponding system of implications about the principal subject. But these implications will not be those comprised in the commonplaces normally implied by literal uses of "man". The new implications must be determined by the pattern of implications associated with literal uses of the word "wolf". Any human traits that can without undue strain be talked about in " wolf-language" will be rendered prominent, and any that cannot will be pushed into the background. The wolf-metaphor suppresses some details, emphasises others-in short, organizes our view of man.

Suppose I look at the night sky through a piece of heavily smoked glass on which certain lines have been left clear. Then I shall see only the stars that can be made to lie on the lines previously prepared upon the screen, and the stars I do see will be seen as organised by the screen's structure. We can think of a metaphor as such a screen, and the system of " associated commonplaces" of the focal word as the network of lines upon the screen. We can say that the principal subject is "seen through" the metaphorical expression-or, if we prefer, that the principal subject is "projected upon" the field of the subsidiary subject. (In the latter analogy, the implication-system of the focal expression must be taken to determine the "law of projection".)

Or take another example. Suppose I am set the task of describing a battle in words drawn as largely as possible 
from the vocabulary of chess. These latter terms determine a system of implications which will proceed to control my description of the battle. The enforced choice of the chess vocabulary will lead some aspects of the battle to be emphasized, others to be neglected, and all to be organized in a way that would cause much more strain in other modes of description. The chess vocabulary filters and transforms: it ot only selects, it brings forward aspects of the battle tha't might not be seen at all through another medium. (Stars that cannot be seen at all, except through telescopes.)

Nor must we neglect the shifts in attitude that regularly result from the use of metaphorical language. A wolf is (conventionally) a hateful and alarming object; so, to call a man a wolf is to imply that he too is hateful and alarming (and thus to support and reinforce dislogistic attitudes). Again, the vocabulary of chess has its primary uses in a highly artificial setting, where all expression of feeling is formally excluded: to describe a battle as if it were a game of chess is accordingly to exclude, by the choice of language, all the more emotionally disturbing aspects of warfare. (Similar bye-products are not rare in philosophical uses of metaphor.)

A fairly obvious objection to the foregoing sketch of the "interaction view" is that it has to hold that some of the " associated commonplaces" themselves suffer metaphorical change of meaning in the process of transfer from the subsidiary to the principal subject. And these changes, if they occur, can hardly be explained by the account given. The primary metaphor, it might be said, has been analyzed into a set of subordinate metaphors, so the account given is either circular or leads to an infinite regress.

This might be met by denying that all changes of meaning in the "associated commonplaces" must be counted as metaphorical shifts. Many of them are best described as extensions of meaning, because they do not involve apprehended connexions between two systems of concepts. I have not undertaken to explain how such extensions or shifts occur in general, and I do not think any simple account will fit all cases. (It is easy enough to mutter 
" analogy", but closer examination soon shows all kinds of " grounds" for shifts of meaning with context—and even no ground at all, sometimes.)

Secondly, I would not deny that a metaphor may involve a number of subordinate metaphors among its implications. But these subordinate metaphors are, I think, usually intended to be taken less "emphatically", i.e., with less stress upon their implications. (The implications of a metaphor are like the overtones of a musical chord; to attach too much " weight" to them is like trying to make the overtones sound as loud as the main notes-and just as pointless.) In any case, primary and subordinate metaphors will normally belong to the same field of discourse, so that they mutually reinforce one and the same system of implications. Conversely, where substantially new metaphors appear as the primary metaphor is unravelled, there is serious risk of confusion of thought ( $c f$. the customary prohibition against " mixed metaphors").

But the preceeding account of metaphor needs correction, if it is to be reasonably adequate. Reference to " associated commonplaces" will fit the commonest cases where the author simply plays upon the stock of common knowledge (and common misinformation) presumably shared by the reader and himself. But in a poem, or a piece of sustained prose, the writer can establish a novel pattern of implications for the literal uses of the key expressions, prior to using them as vehicles for his metaphors. (An author can do much to suppress unwanted implications of the word "contract ", by explicit discussion of its intended meaning, before he proceeds to develop a contract theory of sovereignty. Or a naturalist who really knows wolves may tell us so much about them that his description of man as a wolf diverges quite markedly from the stock uses of that figure.) Metaphors can be supported by specially constructed systems of implications, as well as by accepted commonplaces; they can be made to measure and need not be reach-me-downs.

It was a simplication, again, to speak as if the implicationsystem of the metaphorical expression remains unaltered by the metaphorical statement. The nature of the intended 
application helps to determine the character of the system to be applied (as though the stars could partly determine the character of the observation-screen by which we looked at them). If to call a man a wolf is to put him in a special light, we must not forget that the metaphor makes the wolf seem more human than he otherwise would.

I hope such complications as these can be accommodated within the outline of an "interaction view" that I have tried to present.

6.

Since I have been making so much use of example and illustration, it may be as well to state explicity (and by way of summary) some of the chief respects in which the "interaction" view recommended differs from a "substitution" or a " comparison" view.

In the form in which I have been expounding it, the "interaction view" is committed to the following seven claims:-

(1) A metaphorical statement has two distinct subjectsa "principal " subject and a "subsidiary" one. ${ }^{21}$

(2) These subjects are often best regarded as " systems of things ", rather than " things ".

(3) The metaphor works by applying to the principal subject a system of " associated implications" characteristic of the subsidiary subject.

(4) These implications usually consist of " commonplaces" about the subsidiary subject, but may, in suitable cases, consist of deviant implications established ad hoc by the writer.

(5) The metaphor selects, emphasizes, suppresses, and

${ }^{21}$ This point has often been made. E.g.:-“"As to metaphorical expression, that is a great excellence in style, when it is used with propriety, for it gives you two ideas for one." (Samuel Johnson, quoted by Richards, op. cit, p. 93.)

The choice of labels for the " subjects" is troublesome. See the "Note on terminology" appended to this paper. 
organizes features of the principal subject by implying statements about it that normally apply to the subsidiary subject.

(6) This involves shifts in meaning of words belonging to the same family or system as the metaphorical expression; and some of these shifts, though not all, may be metaphorical transfers. (The subordinate metaphors are, however; to be read less " emphatically".)

(7) There is, in general, no simple "ground" for the necessary shifts of meaning-no blanket reason why some metaphors work and others fail.

It will be found, upon consideration, that point (1) is incompatible with the simplest forms of a "substitution view", point (7) is formally incompatible with a "comparison view"; while the remaining points elaborate reasons for regarding " comparison views" as inadequate.

But is is easy to overstate the conflicts between these three views. If we were to insist that only examples satisfying all seven of the claims listed above should be allowed to count as "genuine" metaphors, we should restrict the correct uses of the word "metaphor" to a very small number of cases. This would be to advocate a persuasive definition of "metaphor" that would tend to make all metaphors interestingly complex. ${ }^{22}$ And such a deviation from current uses of the word " metaphor " would leave us without a convenient label for the more trivial cases. Now it is in just such trivial cases that "substitution" and " comparison" views sometimes seem nearer the mark than " interaction" views. The point might be met by classifying metaphors as instances of substitution, comparison, or interaction. Only the last kind are of importance in philosophy.

For substitution-metaphors and comparison-metaphors

${ }^{22}$ I can sympathise with Empson's contention that " The term ['metaphor'] had better correspond to what the speakers themselves feel to be a rich or suggestive or persuasive use of a word, rather than include uses like the leg of a table" (The Structure of Complex Words, p. 333). But there is the opposite danger, also, of making metaphors too important by definition, and so narrowing our view of the subject excessively. 
can be replaced by literal translations (with possible exception for the case of catachresis)-by sacrificing some of the charm, vivacity, or wit of the original, but with no loss of cognitive content. But "interaction-metaphors" are not expendable. Their mode of operation requires the reader to use a system of implications (a system of " commonplaces" -or a special system established for the purpose in hand) as a means for selecting, emphasizing, and organizing relations in a different field. This use of a "subsidiary subject" to foster insight into a "principal subject" is a distinctive intellectual operation (though one familiar enough through our experiences of learning anything whatever), demanding simultaneous awareness of both subjects but not reducible to any comparison between the two.

Suppose we try to state the cognitive content of an interaction-metaphor in " plain language". Up to a point, we may succeed in stating a number of the relevant relations between the two subjects (though in view of the extension of meaning accompanying the shift in the subsidiary subjects implication system, too much must not be expected of the literal paraphrase). But the set of literal statements so obtained will not have the same power to inform and enlighten as the original. For one thing, the implications, previously left for a suitable reader to educe for himself, with a nice feeling for their relative priorities and degrees of importance, are now presented explicitly as though having equal weight. The literal paraphrase inevitably says too much-and with the wrong emphasis. One of the points I most wish to stress is that the loss in such cases is a loss in cognitive content; the relevant weakness of the literal paraphrase is not that it may be tiresomely prolix or boringly explicit-or deficient in qualities of style; it fails to be a translation because it fails to give the insight that the metaphor did.

But " explication", or elaboration of the metaphor's grounds, if not regarded as an adequate cognitive substitute for the original, may be extremely valuable. A powerful metaphor will no more be harmed by such probing than a musical masterpiece by analysis of its harmonic and melodic 


\section{structure. No doubt metaphors are dangerous-and per- haps especially so in philosophy. But a prohibition against their use would be a wilful and harmful restriction upon our powers of inquiry. ${ }^{23}$}

${ }^{23}$ (A note on terminology) : For metaphors that fit a substitution or comparison view, the factors needing to be distinguished are:-(i) some word or expression $E$; (ii) occurring in some verbal " frame " $F$; so that (iii) $F(E)$ is the metaphorical statement in question; (iv) the meaning $m^{\prime}(E)$ which $E$ has in $F(E)$; (v) which is the same as the literal meaning, $m(X)$, of some literal synomyn, $X$. A sufficient technical vocabulary would be: "metaphorical expression" (for $E)$, " metaphorical statement" (for $F(E)$ ), " metaphorical meaning " (for $\mathrm{m}$ ') and " literal meaning" (for $m$ ).

Where the interaction view is appropriate, the situation is more complicated. We may also need to refer (vi) to the principal subject of $F(E)$, say $P$ (roughly, what the statement is " really" about), (vii) the subsidiary subject, $S$ (what $F(E)$ would be about if read literally); (viii) the relevant system of implications, $I$, connected with $S$; and (ix) the resulting system of attributions, $A$, asserted of $P$. We must accept at least so much complexity if we agree that the meaning of $E$ in its setting $F$ depends upon the transformation of $I$ into $A$ by using language, normally applied to $S$, to apply to $P$ instead.

Richards has suggested using the words "tenor" and "vehicle" for the two " thoughts" which, in his view, are " active together" (for " the two ideas that metaphor, at its simplest, gives us ", Op. cit., p. 96, my italics) and urges that we reserve " the word "metaphor" for the whole double unit" (Ib.). But this picture of two ideas working upon each other is an inconvenient fiction. And it is significant that Richards himself soon lapses into speaking of "tenor" and "vehicle" as " things" (e.g. on p. 118). Richards" "vehicle" vacillates in reference between the metaphorical expression $(E)$, the subsidiary subject $(S)$ and the connected implication system $(I)$. It is less clear what his "tenor" means: sometimes it stands for the principal subject $(P)$, sometimes for the implications connected with that subject (which I have not symbolized above), sometimes, in spite of Richards' own intentions, for the resultant meaning (or as we might say the " full import") of $E$ in its context, $F(E)$.

There is probably no hope of getting an accepted terminology so long as writers upon the subject are still so much at variance with one another. 